\title{
Relapse of Graves' disease following SARS-CoV-2 infection: A case report and brief literature review
}

\author{
SAEED RASHAAD MOHAMMED ${ }^{1}$, MALLIKA TRIPATHI $^{1}$, NARINE MACK $^{2}$ and SURUJPAL TEELUCKSINGH $^{1}$ \\ ${ }^{1}$ Department of Clinical Medical Sciences, Faculty of Medical Sciences, The University of the West Indies, \\ St. Augustine Campus, St. Augustine; ${ }^{2}$ San Fernando General Hospital, South West Regional Health Authority, \\ San Fernando, Trinidad and Tobago
}

Received October 20, 2021; Accepted December 20, 2021

DOI: $10.3892 / \mathrm{mi} .2021 .25$

\begin{abstract}
The interaction between severe acute respiratory syndrome coronavirus 2 (SARS-CoV-2) and autoimmune thyroid disease is an emerging phenomenon. The present study describes the case of a 28-year-old female who experienced a relapse of Graves' disease following SARS-CoV-2 infection. She was biochemically euthyroid for 2 years prior to COVID-19 infection. However, she began experiencing palpitations, increased sweating and tremors of the hands 9 days after being diagnosed with COVID-19-related pneumonia. In addition to presenting this case, a comparison is made of this case to similar reports and the possible mechanisms underlying the association between SARS-CoV-2 and Graves' disease are discussed. One is a direct result of viral uptake by thyroid cells, while another is a result of the hyperinflammatory 'cytokine storm' and its effects on the hypothalamic-pituitary-thyroid axis and T-cell immunity.
\end{abstract}

\section{Introduction}

The interaction between severe acute respiratory syndrome coronavirus 2 (SARS-CoV-2) and autoimmune disease is an emerging phenomenon, with numerous reports of patients with COVID-19 developing autoantibodies and $>10$ distinct autoimmune diseases $(1,2)$. Thyroid disease is a common manifestation, with cases of Graves' disease (3), Hashimoto's disease (3) and postpartum thyroiditis (4) subsequent to SARS-CoV-2 infection being reported.

The present study reports a case of a patient who experienced a relapse of Graves' disease following SARS-CoV-2 infection. In addition, this case is compared to similar reports

Correspondence to: Dr Narine Mack, San Fernando General Hospital, South West Regional Health Authority, Independence Avenue, San Fernando, Trinidad and Tobago

E-mail: narinemack0@gmail.com

Key words: Graves' disease, COVID-19, thyroid, severe acute respiratory syndrome coronavirus 2 and the possible mechanisms underlying the association between SARS-CoV-2 and Graves' disease are also discussed.

\section{Case report}

A 28-year-old female from mainland China, currently residing in Trinidad, presented to the San Fernando General Hospital (San Fernando, Trinidad and Tobago) in June, 2021 with a 19-day history of palpitations, increased sweating and tremors of her hands. She had been diagnosed with COVID-19-related pneumonia 28 days earlier. Of note, 5 years prior, she had been treated for Graves' disease medically; however, she had been biochemically euthyroid and off anti-thyroid medications since 2019. Up to April, 2021, she was euthyroid: Free thyroxine (FT4), $13.2 \mathrm{pg} / \mathrm{ml}$ (reference range, 8.9-17.2 pg/ml) and thyroid-stimulating hormone (TSH), $1.1 \mu \mathrm{IU} / \mathrm{ml}$ (reference range, $0.3-4.5 \mu \mathrm{IU} / \mathrm{ml}$ ) and a thyroid ultrasound, also performed in April, 2021, had displayed a mildly enlarged thyroid with no nodules.

In May, 2021, she presented to her local health centre with a non-productive cough, fatigue and weakness. A nasopharyngeal PCR swab test for SARS-CoV-2 yielded positive results and she was diagnosed with COVID-19-related pneumonia. She experienced palpitations, although she attributed these to the intense fear from the diagnosis of COVID-19, as she was afraid she would not survive. Her clinical status was followed via telemedicine; her respiratory symptoms were treated symptomatically and resolved within 5 days. However, her anxiety and palpitations persisted. After 4 days, she began experiencing tremors and increased sweating. She then presented to one of the authors (NM) at San Fernando General Hospital, 28 days after her initial diagnosis of COVID-19. A clinical examination revealed an anxious female, with fine tremor of her hands, tachycardia (pulse, $120 \mathrm{bpm}$ ) and a non-tender diffuse goitre with a bruit. There were no dermatological or ocular features of Graves' disease. Thyroid function tests were consistent with hyperthyroidism: Free triiodothyronine (FT3), $18.3 \mathrm{pg} / \mathrm{ml}$ (reference range, $2.0-4.2 \mathrm{pg} / \mathrm{ml}$ ), FT4, $46.2 \mathrm{pg} / \mathrm{ml}$ (reference range, $8.9-17.2 \mathrm{pg} / \mathrm{ml}$ ) and $\mathrm{TSH}, 0.0 \mu \mathrm{IU} / \mathrm{ml}$ (reference range, 0.3-4.5 $\mu \mathrm{IU} / \mathrm{ml}$ ) (Table I). TSH receptor antibody (TR-Ab) levels were elevated $(3.2 \mathrm{mIU} / \mathrm{ml}$; positive, $>2.0 \mathrm{IU} / \mathrm{l})$, as were thyroid peroxidase antibody levels $(42.5 \mathrm{IU} / \mathrm{ml}$; reference 
Table I. Thyroid function test results.

\begin{tabular}{lcll}
\hline Test & Result & Reference rage & Flag \\
\hline $\begin{array}{l}\text { Thyroid stimulating } \\
\text { hormone }\end{array}$ & 0.0 & $0.3-4.5 \mu \mathrm{IU} / \mathrm{ml}$ & Low \\
Free T4 & & & \\
Free T3 & 46.2 & $8.9-17.2 \mathrm{pg} / \mathrm{ml}$ & High \\
\hline
\end{tabular}

Table II. Thyroid ultrasound report.

Thyroid ultrasound characteristic

Description

Findings The thyroid gland is mildly enlarged and heterogeneous with diffusely increased vascularity. The thyroid gland was larger than usual

No retrosternal extension or tracheal deviation

The right lobe measures $2.4 \times 1.9 \times 6.8 \mathrm{~cm}$

The left lobe measures $2.4 \times 2.4 \times 6.8 \mathrm{~cm}$

The isthmus measures $0.4 \mathrm{~cm}$ AP

There are bilateral, small well-circumscribed, benign-appearing, hypoechoic thyroid nodules measuring up to $0.8 \mathrm{~cm}$ with no dominant nodule on either side

Small reactive anterior cervical lymph nodes were noted, measuring up to $0.3 \mathrm{~cm}$

Impression Moderately-enlarged thyroid (larger than usual), with multiple well-defined, hypoechoic nodules measuring up to $0.8 \mathrm{~cm}$ and diffusely increased vascularity. These appearances are suggestive of Graves' disease

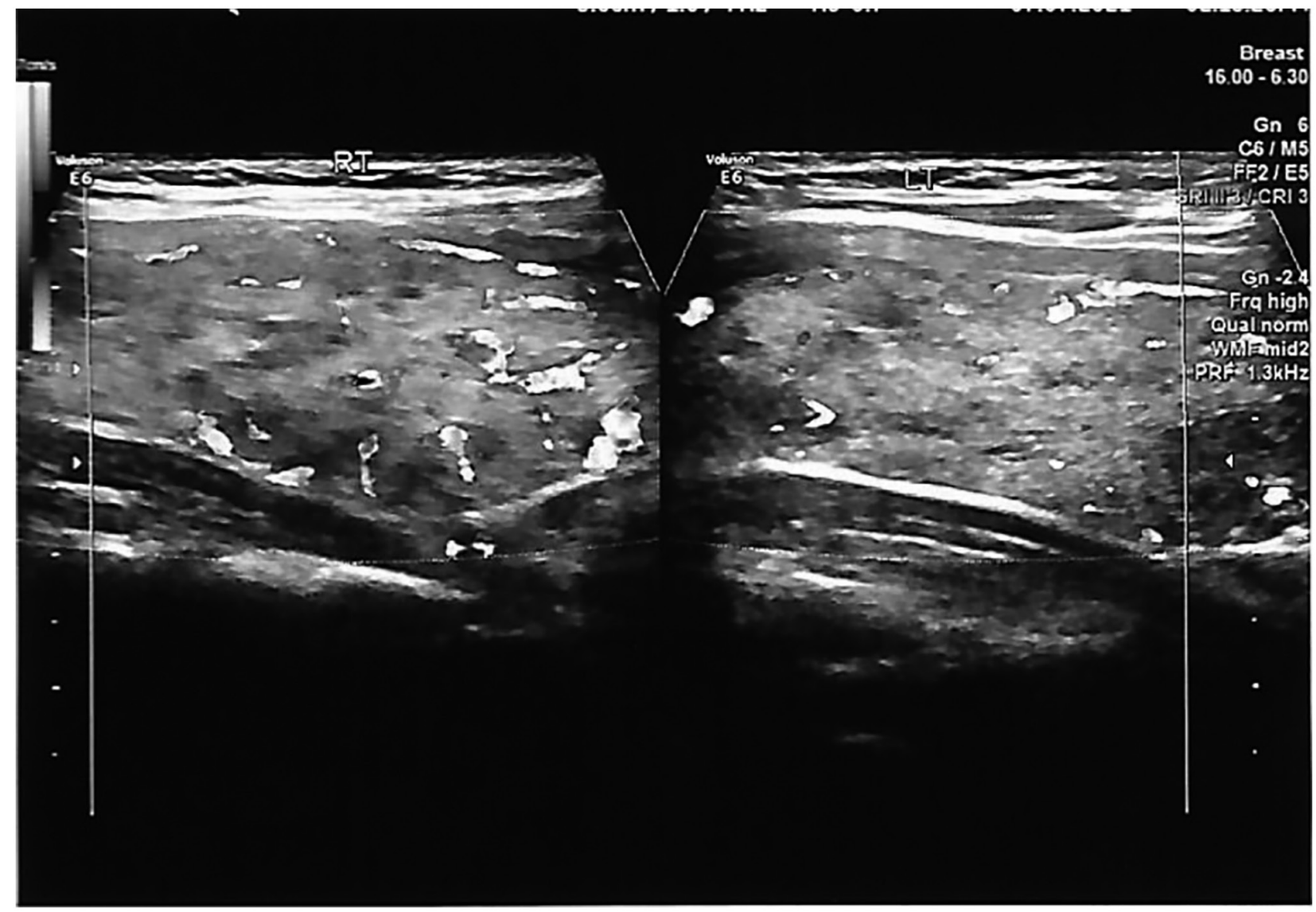

Figure 1. Longitudinal imaging displaying hypervascularity of the thyroid. 


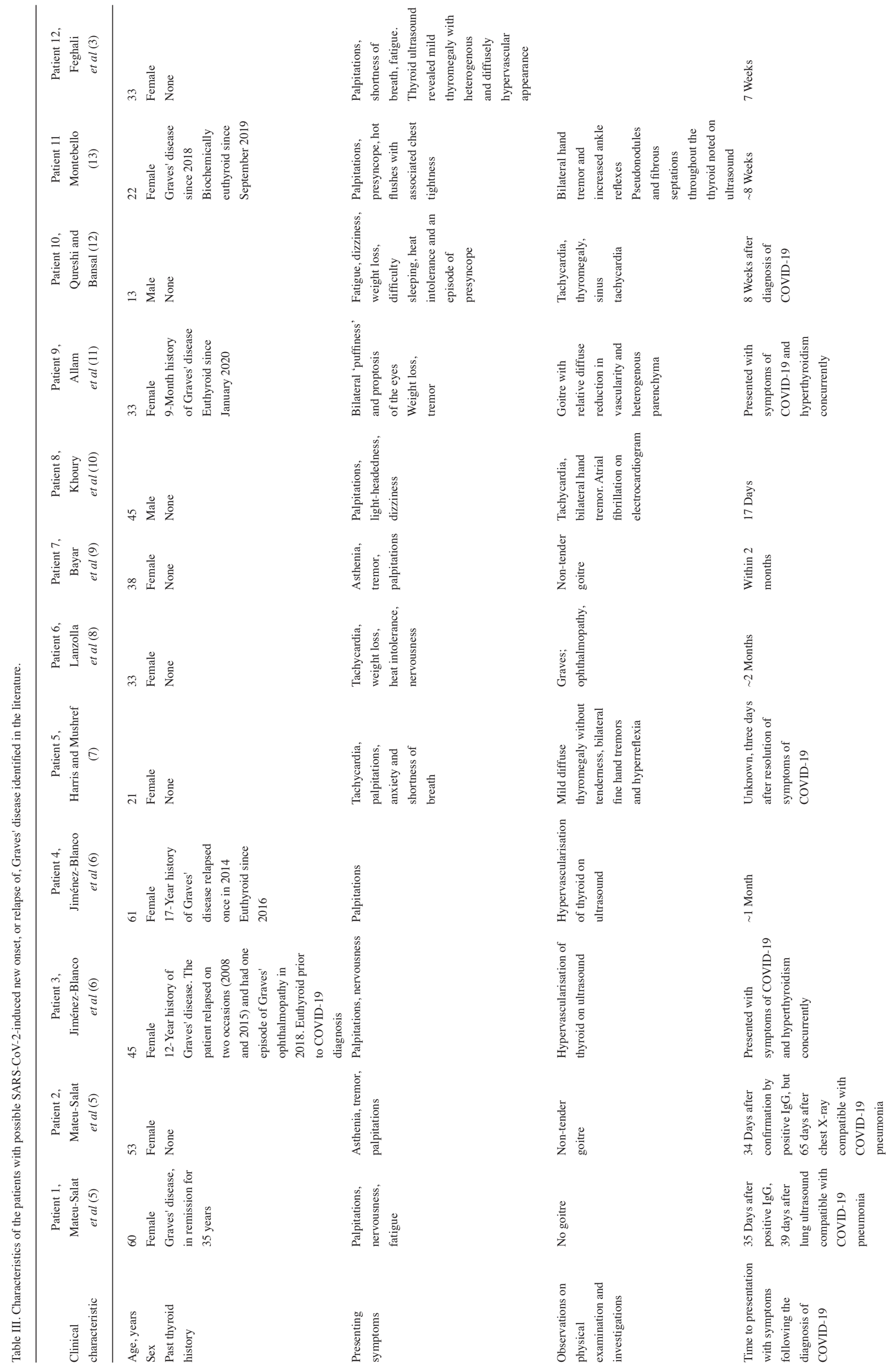




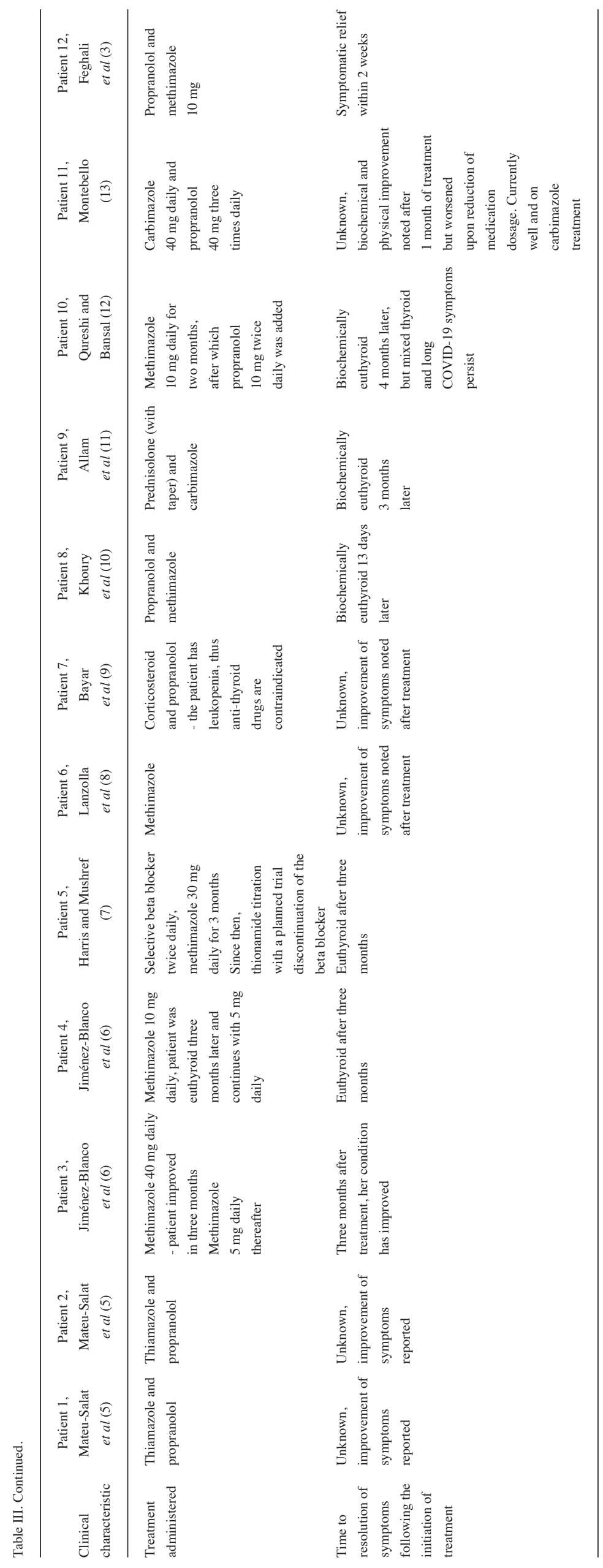


range, 0.0-35.0 $\mathrm{IU} / \mathrm{ml}$ ). A thyroid ultrasound revealed a mildly enlarged goitre with increased vascularity (Fig. 1 and Table II). Blood count, erythrocyte sedimentation rate (ESR) and C-reactive protein (CRP) levels, and liver and renal functions were within normal limits. She was diagnosed with a relapse of Graves' disease and began treatment with carbimazole at $15 \mathrm{mg}$ p.o., b.i.d. and atenolol at $50 \mathrm{mg}$ once daily. The tremors, palpitations and increased sweating ceased 1 week later, whilst her anxiety persisted for several weeks before resolving. She has not reported any complications of COVID-19 and was well at her last follow-up visit.

\section{Discussion}

There have been isolated reports of either relapse of, or newly diagnosed Graves' disease following the diagnosis of SARS-CoV-2. The present study also conducted a literature search evaluating these reports by searching PubMed and Google Scholar for the following terms/keywords: 'Graves' disease', 'SARS-CoV-2' and 'COVID-19'. The characteristics of the patients reported in the literature are presented in Table III.

The majority of the patients identified in the literature presented with symptoms of hyperthyroidism within 2 months of the diagnosis of COVID-19. In most cases, it is uncertain how much time had elapsed between the resolution of the COVID-19-related symptoms and the onset of hyperthyroid symptoms. In the case presented herein, the patient's symptoms began 9 days following the diagnosis of COVID-19. From the cases identified in the literature, five had a history of thyroid disorders (Graves' disease), although they were in remission, i.e., biochemically euthyroid, similar to the patient in the present study. Most cases reportedly experienced an improvement in symptoms soon after the initiation of treatment. In the present case, the tremors, palpitations and perspiration resolved within 1 week of treatment. Graves' disease is the most common cause of hyperthyroidism, and it is thus difficult to state with certainty that SARS-CoV-2 was the cause of these cases, as the virus was not directly evidenced in the thyroid tissue; the temporal relation suggests a role, however.

It is well-established that viral infections can contribute to the pathogenesis of autoimmune thyroid disorders (14). Several plausible mechanisms explaining the interplay between SARS-CoV-2 infection and Graves' disease have been proposed. SARS-CoV-2 enters host cells via the binding of its spike protein to angiotensin-converting enzyme-2 (ACE2) receptors and the subsequent recruitment of transmembrane protease serine 2 (TMPRSS2) to facilitate cytoplasmic entry. The thyroid gland expresses both ACE2 and TMPRSS2 in high quantities, and this may allow SARS-CoV-2 to directly induce thyroid dysfunction (15).

The levels of several cytokines, including IL-6, IL-1 $\beta$, TNF- $\alpha$ and IFN- $\gamma$ are elevated in the hyperinflammatory state induced by SARS-CoV-2. Croce et al (16) noted that these cytokines exert a multitude of effects on the hypothalamic-pituitary-thyroid axis, on circulating thyroid hormone binding proteins and the peripheral metabolism of thyroid hormones. The pathogenesis of Graves' disease is convoluted and the understanding of this disease is rapidly increasing (17). The 'cytokine storm' associated with SARS-CoV-2 may promote the hyperactivity of the Th1/Th17 immune response (18). Th17 lymphocytes synthesize several pro-inflammatory cytokines which may play a role in direct tissue damage and contribute to autoimmune disease (19). It has been postulated that viral-induced Graves' disease may be mediated by Th17 (20). Elevated levels of IL-6 have been reported in patients with Graves' disease (21) and a mechanistic link has been proposed (17).

Psychological stress may contribute to the aetiology of Graves' disease and may thus play a role in relapse (14), further confounding the relationship between SARS-CoV-2 infection and thyroid disease.

Multiple plausible mechanisms may account for the influence of SARS-CoV-2 on thyroid disease. One is a direct result of viral uptake by thyroid cells (15), while another is a result of the hyperinflammatory 'cytokine storm' and its effects on the hypothalamic-pituitary-thyroid axis and T-cell immunity $(16,18,19,20)$.

In conclusion, there is increasing evidence to suggest that SARS-CoV-2 infection may be a precursor for autoimmune disease. The present study reports the case of a 28 -year-old female of Chinese descent with a relapse of Graves' disease 28 days following the diagnosis of COVID-19. Her symptoms began 9 days after a positive nasopharyngeal PCR swab for SARS-CoV-2. Anecdotal data may implicate SARS-CoV-2 as a trigger for relapse of, or new onset Graves' disease.

It is thus recommended that clinicians follow-up patients with COVID-19 with a previous history of autoimmune thyroid disease, as it may trigger a relapse, as in this case. Further research is required to elucidate the exact mechanism(s) underlying the association between SARS-CoV-2 and autoimmune conditions.

\section{Acknowledgements}

Not applicable.

\section{Funding}

No funding was received.

\section{Availability of data and materials}

The datasets used and/or analysed during the current study are available from the corresponding author upon reasonable request.

\section{Authors' contributions}

NM and ST conceptualized the study. All authors (SRM, MT, NM and ST) were involved in the design of the study, in the writing, review and editing of the manuscript, as well as in project administration. NM and ST supervised the study. SRM and MT were involved in the writing of the original draft. SRM, MT and NM were involved in obtaining medical images. NM, SRM, MT and ST were involved in patient care/management. All authors (NM, SRM, MT and ST) confirm the authenticity of all the raw data. All authors have read and approved the final manuscript. 


\section{Ethics approval and consent to participate}

Due to the present study being a retrospective case report, ethical approval was not required. Informed consent was obtained from the patient for all procedures conducted as part of clinical care/management.

\section{Patient consent for publication}

The patient provided consent for the publication of this report.

\section{Competing interests}

All authors declare that they have no competing interests.

\section{References}

1. Dotan A, Muller S, Kanduc D, David P, Halpert G and Shoenfeld Y: The SARS-CoV-2 as an instrumental trigger of autoimmunity. Autoimmun Rev 20: 102792, 2021

2. Liu Y, Sawalha AH and Lu Q: COVID-19 and autoimmune diseases. Curr Opin Rheumatol 33: 155-162, 2021

3. Feghali K, Atallah J and Norman C: Manifestations of thyroid disease post COVID-19 illness: Report of Hashimoto thyroiditis, Graves' disease, and subacute thyroiditis. J Clin Trans Endocrinol Case Rep 22: 100094, 2021.

4. Mizuno S, Inaba H, Kobayashi KI, Kubo K, Ito S, Hirobata T, Inoue $\mathrm{G}$, Akamizu $\mathrm{T}$ and Komiya $\mathrm{N}$ : A case of postpartum thyroiditis following SARS-CoV-2 infection. Endocr J 68: 371-374, 2021.

5. Mateu-Salat M, Urgell E and Chico A: SARS-COV-2 as a trigger for autoimmune disease: Report of two cases of Graves' disease after COVID-19. J Endocrinol Invest 43: 1527-1528, 2020.

6. Jiménez-Blanco S, Pla-Peris B and Marazuela M: COVID-19: A cause of recurrent Graves' hyperthyroidism? J Endocrinol Invest 44: 387-388, 2021.

7. Harris A and AI Mushref MA: Graves' thyrotoxicosis following SARS-CoV-2 infection. AACE Clin Case Rep 7: 14-16, 2021.

8. Lanzolla G, Marcocci C and Marinò M: Graves' disease and Graves' orbitopathy following COVID-19. J Endocrinol Invest 44: 2011-2012, 2021.
9. Bayar I, Tahri S, Hajji E, Ben AB, Sayadi H, Héla M and Inès K: A case of Grave's disease following SARS-Cov 2 infection. Endocrine Abstracts 73: AEP657, 2021.

10. Khoury M, Tripathi P and Narayana S: Abstract \#1017450: COVID-19 Associated Grave's Disease Identified in a 45-year-old Male. Endocrine Practice 27: S186-S187, 2021.

11. Allam MM,El-Zawawy HT, Ahmed SM and Aly Abdelhamid M: Thyroid disease and covid-19 infection: Case series. Clin Case Rep 9: e04225, 2021.

12. Qureshi NK and Bansal SK: Autoimmune thyroid disease and psoriasis vulgaris after COVID-19 in a male teenager. Case Rep Pediatr 2021: 7584729, 2021.

13. Montebello A: Recurrent Graves' disease post SARS-CoV-2 infection. BMJ Case Rep 14: e244714, 2021.

14. Marinò M, Latrofa F, Menconi F, Chiovato L and Vitti P: Role of genetic and non-genetic factors in the etiology of Graves' disease. J Endocrinol Invest 38: 283-294, 2015.

15. Duntas LH and Jonklaas J: COVID-19 and thyroid diseases: A bidirectional impact. J Endocr Soc 5: bvab076, 2021.

16. Croce L, Gangemi D, Ancona G, Liboà F, Bendotti G, Minelli L and Chiovato L: The cytokine storm and thyroid hormone changes in COVID-19. J Endocrinol Invest 44: 891-904, 2021.

17. Rajaii F, McCoy AN and Smith TJ: Cytokines as villains and potential therapeutic targets in thyroid-associated ophthalmopathy: From bench to bedside. Expert Rev Ophthalmol 9: 227-234, 2014.

18. Lania A, Sandri MT, Cellini M, Mirani M, Lavezzi E and Mazziotti G: Thyrotoxicosis in patients with COVID-19: The THYRCOV study. Eur J Endocrinol 183: 381-387, 2020.

19. Costela-Ruiz VJ, Illescas-Montes R, Puerta-Puerta JM, Ruiz C and Melguizo-Rodríguez L: SARS-CoV-2 infection: The role of cytokines in COVID-19 disease. Cytokine Growth Factor Rev 54: 62-75, 2020.

20. Murugan AK and Alzahrani AS: SARS-CoV-2 plays a pivotal role in inducing hyperthyroidism of Graves' disease. Endocrine 73: 243-254, 2021.

21. Salvi M, Girasole G, Pedrazzoni M, Passeri M, Giuliani N, Minelli R, Braverman LE and Roti E: Increased serum concentrations of interleukin-6 (IL-6) and soluble IL-6 receptor in patients with Graves' disease. J Clin Endocrinol Metab 81: 2976-2979, 1996.

(i) $\Theta$ This work is licensed under a Creative Commons Attribution-NonCommercial-NoDerivatives 4.0 International (CC BY-NC-ND 4.0) License. 